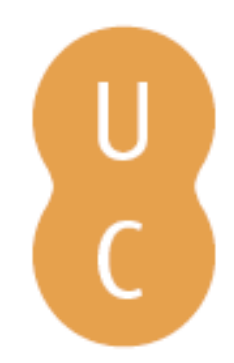

\title{
nommalina
}

\section{Fatores de aquisição e manutenção da qualidade gemológica dos berilos dos pegmáticos do Licungo (Zambélia, Moçambique)}

\author{
Autor(es): $\quad$ Moiana, M.; Gomes, C. A. L.; Dias, P. A. \\ Publicado por: Imprensa da Universidade de Coimbra \\ URL \\ persistente: URI:http://hdl.handle.net/10316.2/31445 \\ DOI: $\quad$ DOI:http://dx.doi.org/10.14195/978-989-26-0534-0_29 \\ Accessed : $\quad$ 26-Apr-2023 15:23:43
}

A navegação consulta e descarregamento dos títulos inseridos nas Bibliotecas Digitais UC Digitalis, UC Pombalina e UC Impactum, pressupõem a aceitação plena e sem reservas dos Termos e Condições de Uso destas Bibliotecas Digitais, disponíveis em https://digitalis.uc.pt/pt-pt/termos.

Conforme exposto nos referidos Termos e Condições de Uso, o descarregamento de títulos de acesso restrito requer uma licença válida de autorização devendo o utilizador aceder ao(s) documento(s) a partir de um endereço de IP da instituição detentora da supramencionada licença.

Ao utilizador é apenas permitido o descarregamento para uso pessoal, pelo que o emprego do(s) título(s) descarregado(s) para outro fim, designadamente comercial, carece de autorização do respetivo autor ou editor da obra.

Na medida em que todas as obras da UC Digitalis se encontram protegidas pelo Código do Direito de Autor e Direitos Conexos e demais legislação aplicável, toda a cópia, parcial ou total, deste documento, nos casos em que é legalmente admitida, deverá conter ou fazer-se acompanhar por este aviso.

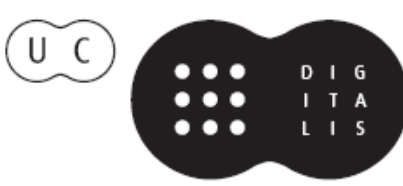





\title{
FATORES DE AQUISIÇÃO E MANUTENÇÃO DA QUALIDADE GEMOLÓGICA DOS BERILOS DOS PEGMATITOS DO LICUNGO (ZAMBÉZIA, MOÇAMBIQUE)
}

\author{
CONDITIONS FOR GENERATION AND PERSISTENCE \\ OF GEM-BERYL IN LICUNGO PEGMATITES \\ (ZAMBEZIA, MOZAMBIQUE)
}

Resumo - No Campo Pegmatítico do Licungo ocorrem berilos azuis que atingem qualidade gemológica como cristais euédricos pequenos (c $<8 \mathrm{~cm}$ e a $<1,5 \mathrm{~cm}$ ) no Domínio Estrutural Sul (em Azul Mais) e como porções nodulares anédricas (10-15 mm de diâmetro; > 2 g) no interior de gigacristais no Domínio Estrutural Norte (Ígaro e Vila Maior). Em ambos os casos, trata-se de águas-marinhas primárias, com altos teores de Fe transferido a partir de rochas meta-ultramáficas encaixantes e altos teores de álcalis preservados perante eventos deformacionais e hidrotermais ulteriores.

Palavras-chaves - Pegmatito; Berilo; Água-marinha; Substituição iónica

Abstract - At the Licungo Pegmatitic Field, blue beryl gemstones occur as small euedric crystals $(c<8 \mathrm{~cm}$ and $a<1,5 \mathrm{~cm})$ in the Southern Structural Domain as well as augen anedric fragments (10-15 mm diameter; $>2 \mathrm{~g}$ ) inside large beryl crystals in the Northern Structural Domain. In both domains, the crystals are primary aquamarines with high Fe content transferred from meta-ultramafic country rocks and high alkali content. The contents of Fe and alkali were preserved even during the deformation and hydrothermal fluids interaction.

Keywords - Pegmatite; Beryl; Aquamarine; Ionic replacement

\footnotetext{
CIG-R, Universidade do Minho, Portugal; moiana2000@yahoo.com.br
}

2 Museu Nacional de Geologia, Moçambique 


\section{1 - Introdução}

O Campo Pegmatítico do Licungo (CPL) é uma importante fonte de matérias-primas pela sua diversidade mineralógica, que inclui recursos a base de feldspatos pertíticos e quartzo para a aplicação em cerâmica, quartzo ótico, berilo, minérios metálicos e gemas. Os berilos encontram-se distribuídos ao longo de todo o CPL, principalmente os de cor azul, que em alguns casos atingem um azul intenso próprio das águas-marinhas designadas true-blue (MOIANA, 2010). É na perspetiva de encontrar guias geoquímicos e estruturais que conduzam à localização de gemshoots (das águas-marinhas) que se elaborou o presente trabalho. Especificamente procura-se:

- identificar a génese da coloração azul das águas-marinhas do Licungo;

- identificar os fatores responsáveis pela persistência após a génese das características gemológicas;

- estabelecer a diversidade dos corpos ou zonas pegmatíticas que podem ser portadores das águas-marinhas.

\section{2-Metodologia}

Amostras de berilo, colhidas em corpos pegmatíticos expostos em trabalhos de pesquisa e prospeção, foram sujeitas a preparação para análise química. Obtiveram-se secçóes polidas de berilos que foram analisadas em microssonda eletrónica (ME) JEOL, modelo JXA 8500-F, disponível no Laboratório Nacional de Energia e Geologia de Portugal (LNEG). A microssonda está equipada com 5 espectrómetros de dispersão de comprimentos de onda e 1 de dispersão de energia, e as análises foram efetuadas a $15 \mathrm{kV}, 10$ a $30 \mu \mathrm{A}$, sendo o diâmetro do feixe de $2 \mu \mathrm{m}$. Os tempos de contagem para os picos significativos de cada elemento foram de $20 \mathrm{~s}$. Os resultados da $\mathrm{ME}$, em \% do peso, foram convertidos em Átomos por Fórmula Unitária (apfu).

\section{3 - Enquadramento geológico e estrutural}

O CPL localiza-se no Distrito de Mocuba, Província da Zambézia, na região central de Moçambique. No Domínio do Licungo foram objetos de investigação os corpos pegmatíticos situados na margem oriental do Rio Licungo, designadamente o Ígaro (Ig), Vila Maior (VM), Mugulama (Mg), Careca (Cc), Bismuto (Bi), Murribane (Mb), Virgínia (Vg), Scheelite (Sc), Melatube (Mt) e Azul Mais (Az) (Fig. 1). Foi, ainda, objeto de análise, um corpo pegmatítico do Domínio Lugela $(\mathrm{Lg})$, situado a $25 \mathrm{~km}$ a NW do Ígaro.

Os corpos pegmatíticos estão implantados em rochas metamórficas, metassedimentares a metavulcânicas, desde félsicas a básicas, de idade Proterozoica, que se relacionam com um evento geotectónico de larga escala, expresso na Cadeia Moçambicana. Nestas condiçóes, a natureza das rochas regionais deve ter desempenhado um papel determinante na troca de constituintes por metassomatismo, levando à formação de fases minerais e associaçóes paragenéticas características, tanto na encaixante, como no interior dos pegmatitos. 
No CPL predominam rochas encaixantes tais como gnaisses graníticos, gnaisses anfibólicos a anfibolitos e gnaisses metassedimentares psamíticos a pelíticos (Fig. 1), afetadas pela deformação regional que facultou o aparecimento dos espaços dilatacionais, os quais posteriormente acolheram os pegmatitos.

As estruturas que expressam a deformação organizam-se em domínios diferenciados (Fig. 2):

\section{1 - Domínio Estrutural Norte}

Destacam-se alinhamentos estruturais NNE-SSW e NNW-SSE, provavelmente de idade Pan-Africana que acolheram pegmatitos de grandes dimensóes, com geometria subhorizontal ou subvertical nas ruturas associadas aos cavalgamentos. Os pegmatitos são atravessados pela superfície $\mathrm{Sn}+2$ que se observa nas rochas encaixantes. Estão identificados neste domínio três grandes corpos pegmatíticos - Vila Maior, Ígaro e Mugulama - com uma estrutura interna muito simples, mostrando bordos espessos de pegmatito gráfico, zonas intermédias pouco possantes com pertite e núcleos de quartzo volumosos. Os berilos dispóem-se ao longo das frentes de transição, entre a zona intermédia e o núcleo de quartzo, irradiando daí para o interior do núcleo. Os berilos azuis-gemas ocorrem como nódulos anédricos localizados no interior dos cristais de berilo de maiores dimensóes em Vila Maior, Ígaro e Mugulama, e em gigacristais de berilo do Lugela.
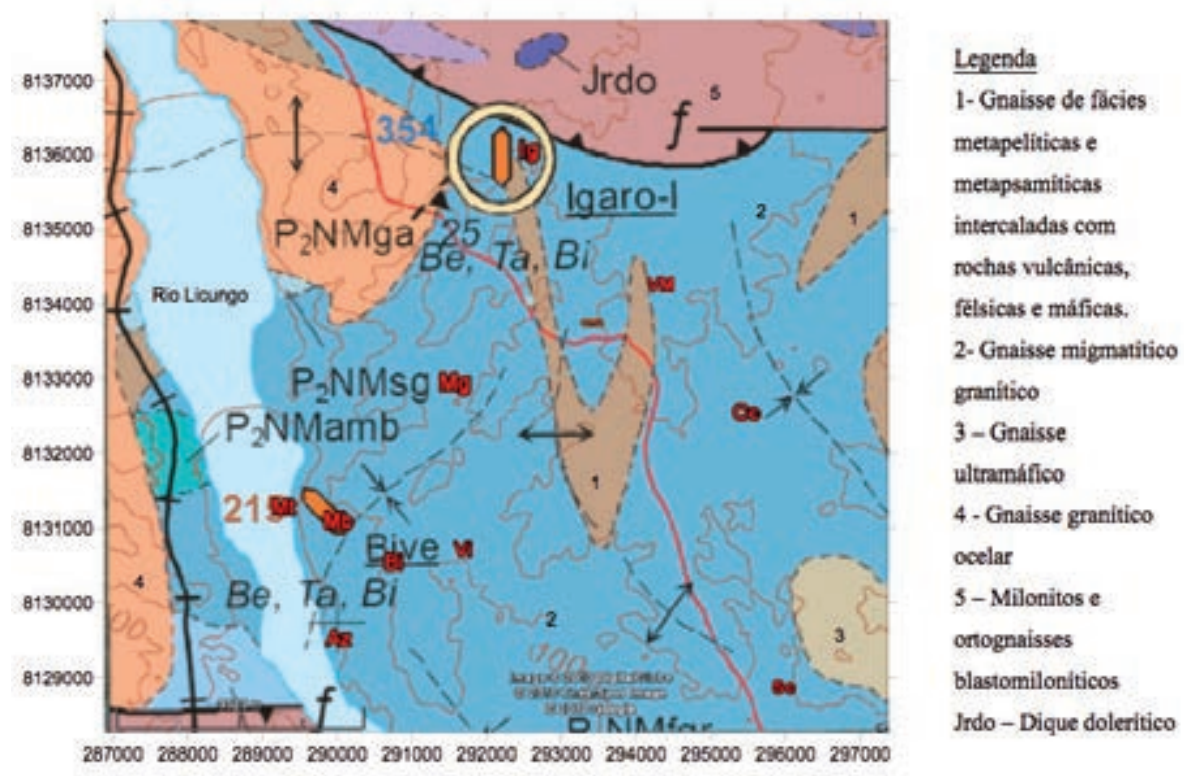

Fig. 1 - Carta geológica da área em estudo. Extrato da folha 1637 à escala 1:250000, de Errego (Direcçấo Nacional de Geologia, Moçambique).

Símbolos de localidades descritos no texto. 


\section{2 - Domínio Estrutural Sul}

No Domínio Sul, os pegmatitos situados na faixa Melatube-Vieira e zonas periféricas são tardios. As estruturas que acolheram estes pegmatitos induziram uma pequena espessura de caixas filonianas, um número muito grande de pequenos corpos individualizados e uma assinalável apetência à mineralização em água-marinha.

O Domínio Sul é condicionado pelo corredor de cisalhamento sinestrógiro Melatube-Vieira, que trunca a Sul a imbricação de mantos e dobras típicas do Domínio Norte. Os pegmatitos situam-se em sítios distensivos definidos em corredores de cisalhamento NNE-SSW estabelecidos em Dn+1 e, muito em especial, no cruzamento com o corredor Melatube-Vieira (NNW-SSE). Os filóes são afetados em $\mathrm{Dn}+2$ por deslocamentos tangenciais expressos em cavalgamentos de muito baixo ângulo, que tendem posteriormente para desligamentos sinestrógiros com "boudinage", segundo a direção WNW-ESE (DIAS et al., 2008).

Fazem parte deste domínio, os corpos Careca, Bismuto, Murribane, Virgínia, Scheelite, Melatube e Azul Mais, com estrutura interna simples, constituída por núcleos de quartzo pouco possantes, zona intermédia com pertites cremes a brancas e bordadura constituída por massas com intercrescimento gráfico quartzo-feldspático. Os berilos, nestes corpos, ocorrem em pequena dimensão, na zona intermédia, manifestando tendência gemológica em Melatube e boa qualidade gema em Azul Mais.
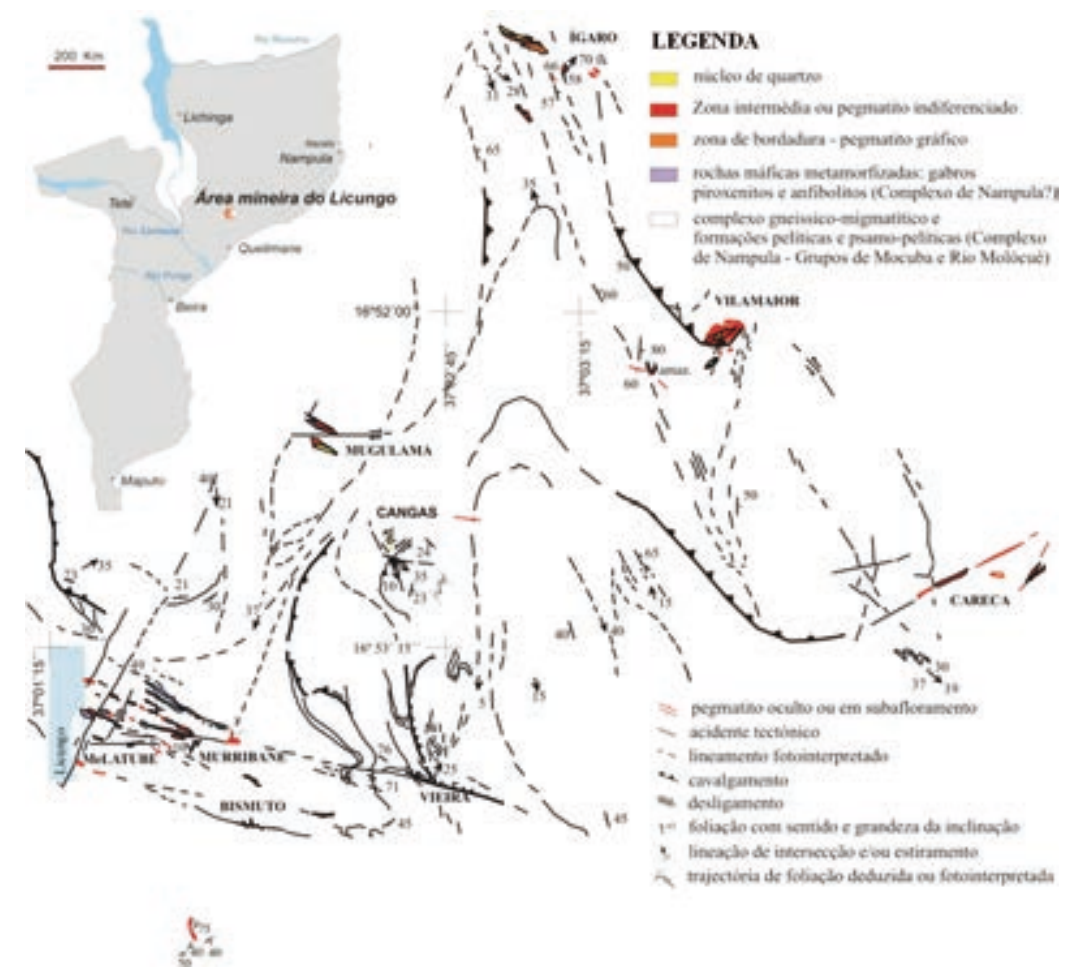

Fig. 2 - Estruturas geológicas e enquadramento estrutural dos fulcros pegmatíticos (MOIANA et al., 2010). 


\section{4 - Mineroquímica do berilo e origem da cor azul das águas-marinhas}

As cores das variedades do berilo $\left(\mathrm{Be}_{3} \mathrm{Al}_{2} \mathrm{Si}_{6} \mathrm{O}_{18}\right)$ são atribuídas à substituição na estrutura cristalina, de ióes em sítios intersticiais ou em sítios estruturais vazios (canais). Segundo POLLI et al. (2006), as substituições mais comuns, que se refletem na cor dos berilos, dizem respeito aos iōes $\mathrm{Cr}^{3+}, \mathrm{Fe}^{2+}, \mathrm{Fe}^{3+}, \mathrm{Mn}^{2+}, \mathrm{Mn}^{3+} \mathrm{e} \mathrm{V}^{5+}$, sendo, também, relevante, a correlação positiva entre os álcalis $\left(\mathrm{Na}^{+}, \mathrm{Rb}^{+}\right.$e Cs $\left.{ }^{+}\right)$e cor, no caso de variedades de berilo como a morganite, água-marinha e goshenite. Estes elementos, que POLLI et al. (2006) e vários outros autores consideram influentes sobre a cor dos berilos, foram analisados. No caso do CPL, os resultados dessas análises estão apresentados na tabela 1 .

$\mathrm{O} \mathrm{Fe}^{2+}$ e Ti, ióes considerados responsáveis pela cor azul (TVERIANKIN et al., 1983), mostram tendências díspares. Vários berilos apresentam teores muito baixos em Ti. Apenas uma análise de uma fase com cor azul intensa tem teores elevados de Ti (Fig. 3).

$\mathrm{O}$ Fe mostra teores relativamente altos. Parece verificar-se uma certa gradação desde teores baixos para os berilos náo azuis e azuis-claros até teores mais altos para uma cor azul mais intensa (Fig. 3).
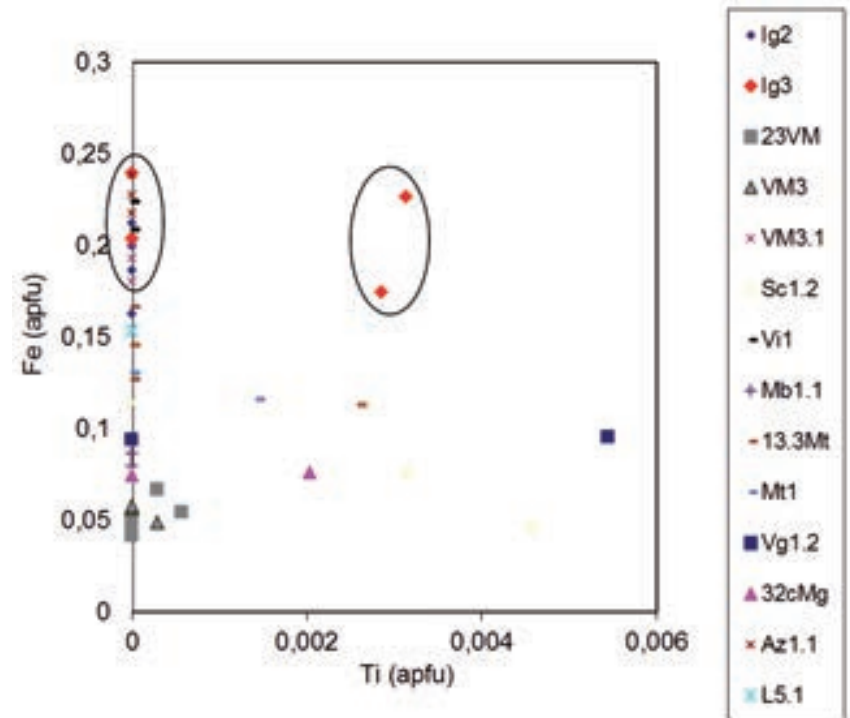

Fig. 3 - Correlação entre iôes eventualmente relacionados com a cor azul dos berilos. Estão em elipse as projeçóes correspondentes a berilos-gema. Designaçóes dos pegmatitos como na fig. 1 .

Para aferir a localizaçáo do Fe na estrutura dos berilos procurou-se estabelecer uma correlação entre este e o $\mathrm{Al}$ (Fig. 4). A boa correlação negativa sugere que ambos os elementos se inter-substituem, principalmente em locais octaédricos.

$\mathrm{O} F$ foi provavelmente transferido das rochas máficas encaixantes durante a formação dos pegmatitos ou incorporou-se durante processos hidrotermais subsequentes, que promoveram a alteraçáo em subsolidus do berilo, com substituição do $\mathrm{Al}$ por $\mathrm{Fe}$, em maior percentagem, e por $\mathrm{Mn}$ e $\mathrm{Mg}$, em menores proporçóes. 


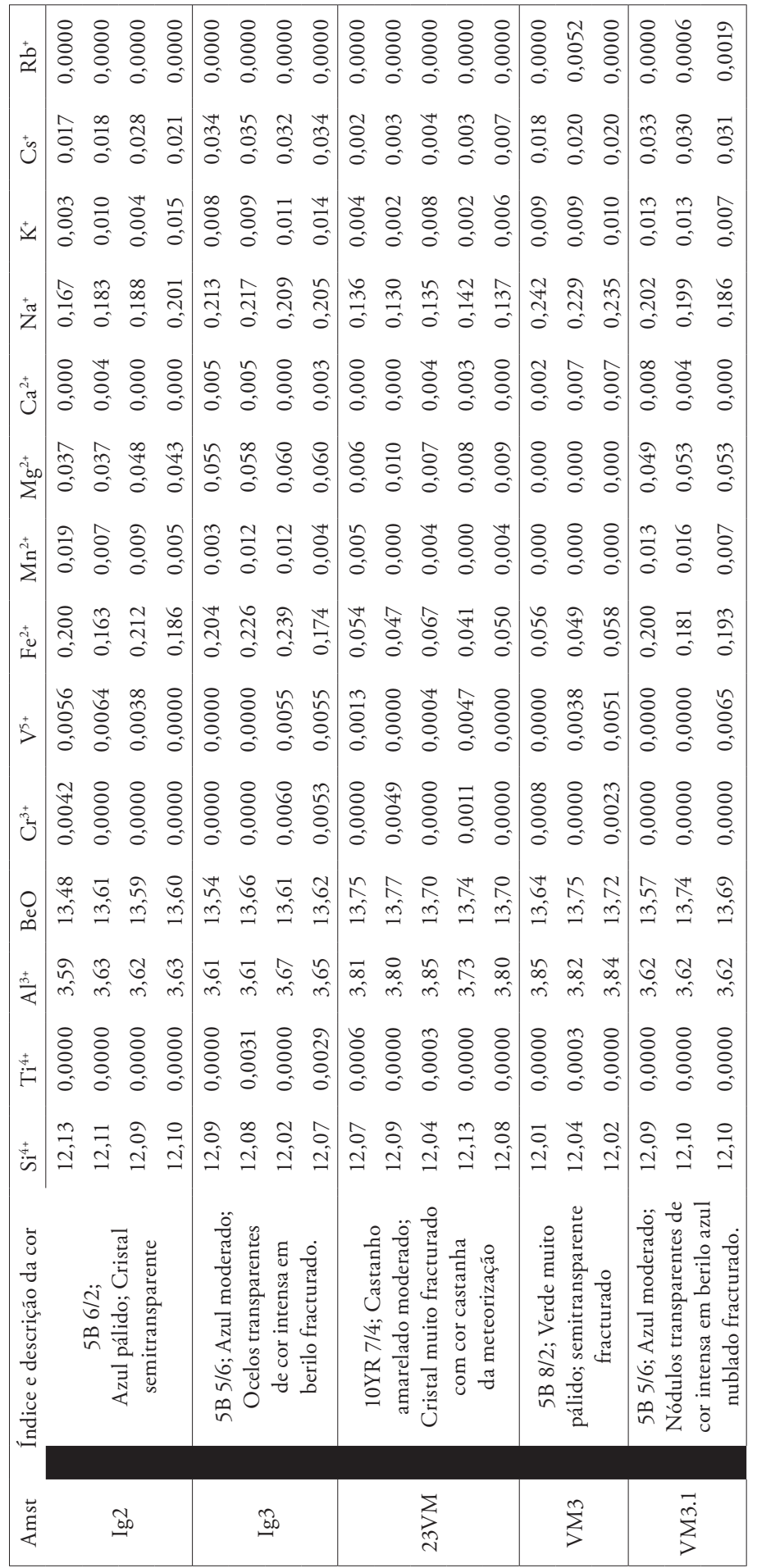




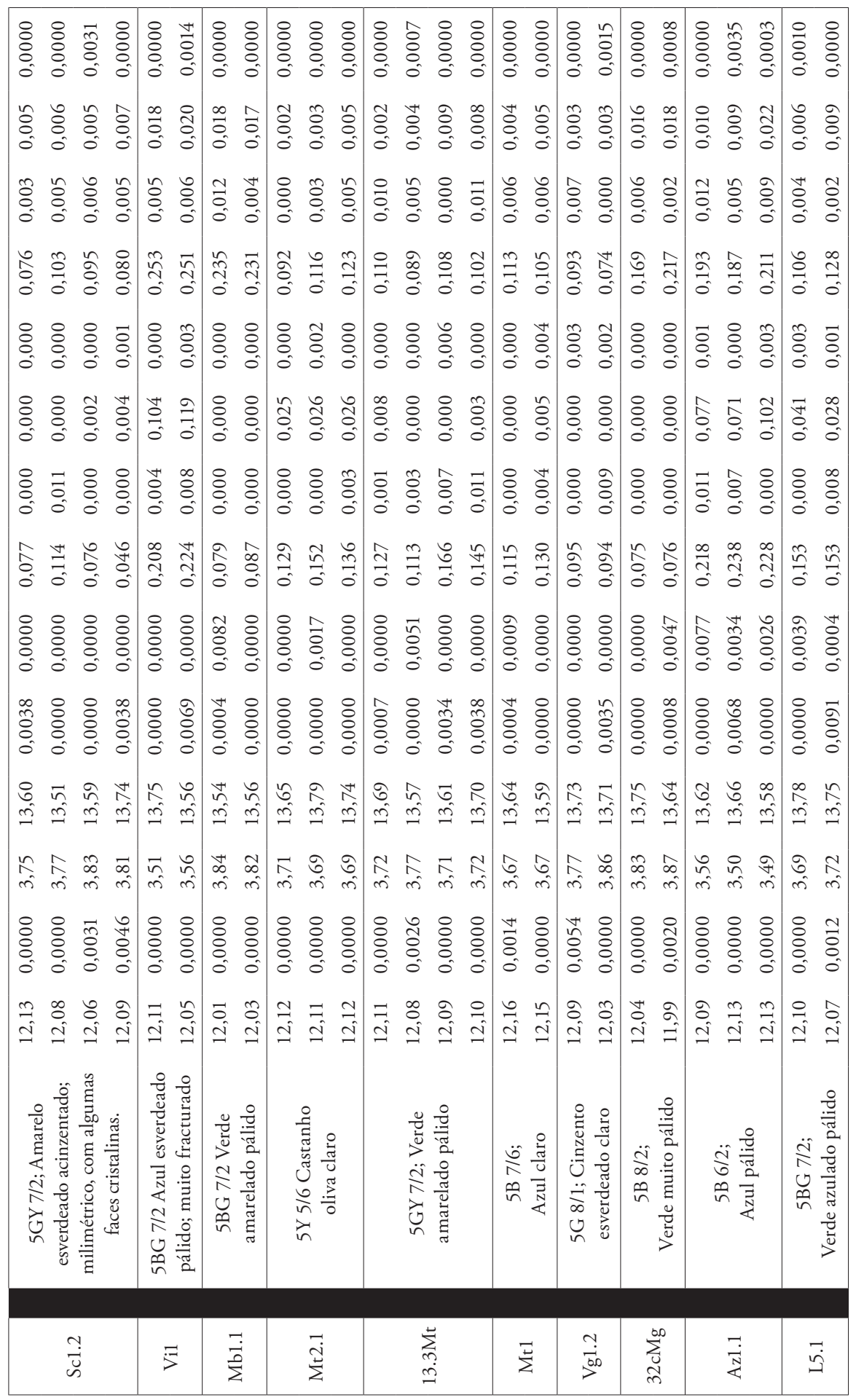




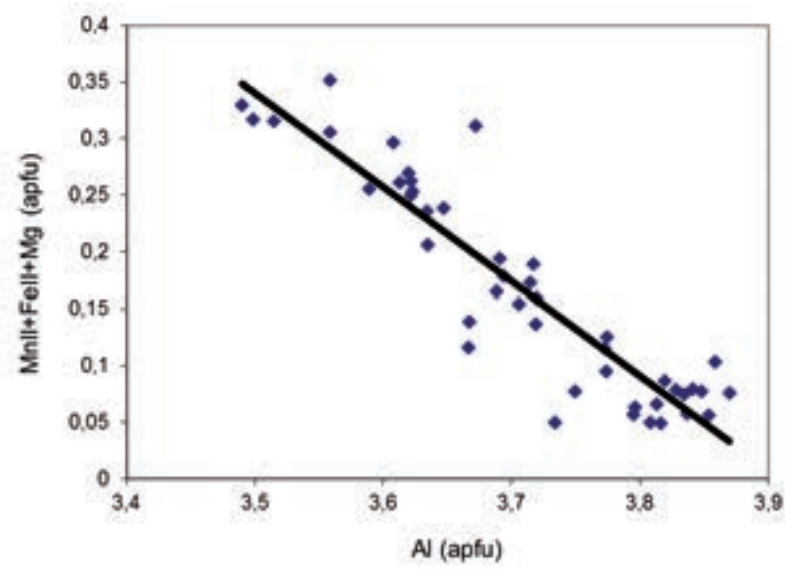

Fig. 4 - Correlaçấo entre $\mathrm{Al}$ e iôes divalentes $(\mathrm{Fe}+\mathrm{Mn}+\mathrm{Mg})$.

Entre o Fe e os álcalis observam-se duas tendências de correlação positiva, que refletem a ocorrência diferenciada em dois agrupamentos espaciais dos corpos pegmatíticos (Fig. 5).

Os berilos de Azul Mais, Vieira, Igaro, Melatube, Lugela, Virgínia, Sheelite e parte de Vila Maior são projetados numa linha de tendência de menor gradiente, e os de Murribane, Vila Maior e Mugulama têm uma tendência que, comparativamente, denota maior enriquecimento em álcalis.

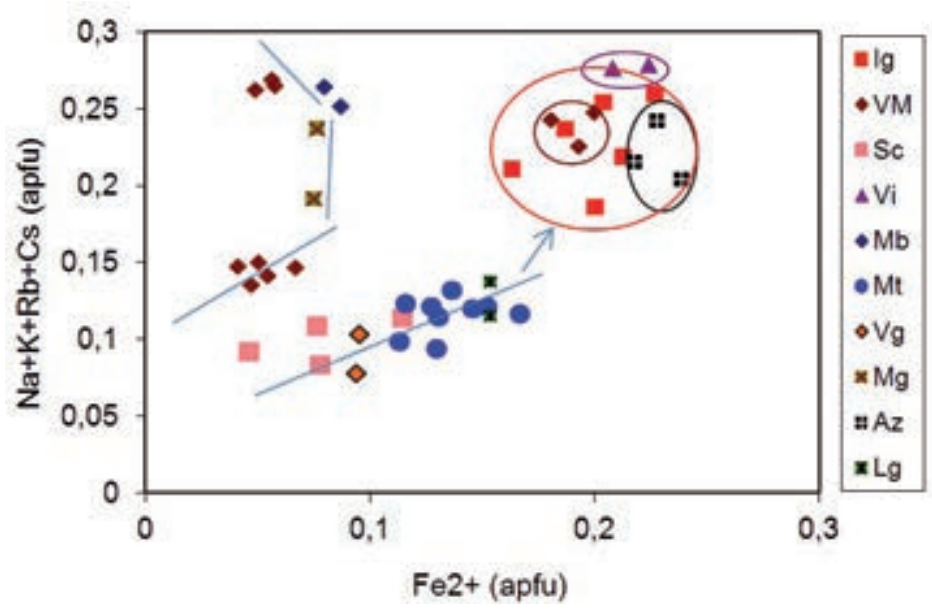

Fig. 5 - Correlação entre $\mathrm{Fe}^{2+}$ e $\mathrm{Na}+\mathrm{K}+\mathrm{Rb}+\mathrm{Cs}$.

As correlaçôes positivas sugerem que a substituição de $\mathrm{Al}$ por iôes divalentes, principalmente o Fe, nos espaços octaédricos, é acompanhada pela entrada de álcalis nos canais para compensar o défice de cargas positivas. As seguintes reaçôes de substituição são mais prováveis: 
$\mathrm{Fe}^{2+(+ \text { espaço octaédrico) }}+\mathrm{Na}^{+ \text {(canal) }}=\mathrm{Al}^{3+(- \text { espaço octaédrico) }}+[\text { vazio }]^{\text {canal }}($ FRANZ et al., 1986)

ou

$\left(\mathrm{Fe}^{2+}, \mathrm{Mn}^{2+}, \mathrm{Mg}^{2+}\right)^{(+ \text {espaço octaédrico) }}+\left(\mathrm{Na}^{+}, \mathrm{K}^{+}, \mathrm{Rb}^{+}, \mathrm{Cs}^{+}\right)^{(\text {canal })}=\mathrm{Al}^{3+(- \text { espaço octaédrico) }}+[\text { vazio }]^{\text {canal }}$

Os berilos de boa qualidade estão destacados na parte superior da linha de menor gradiente da Fig. 5, o que permite concluir que se tornam mais azuis e com melhor carácter gemológico quando têm simultaneamente elevado teor em Fe e em álcalis.

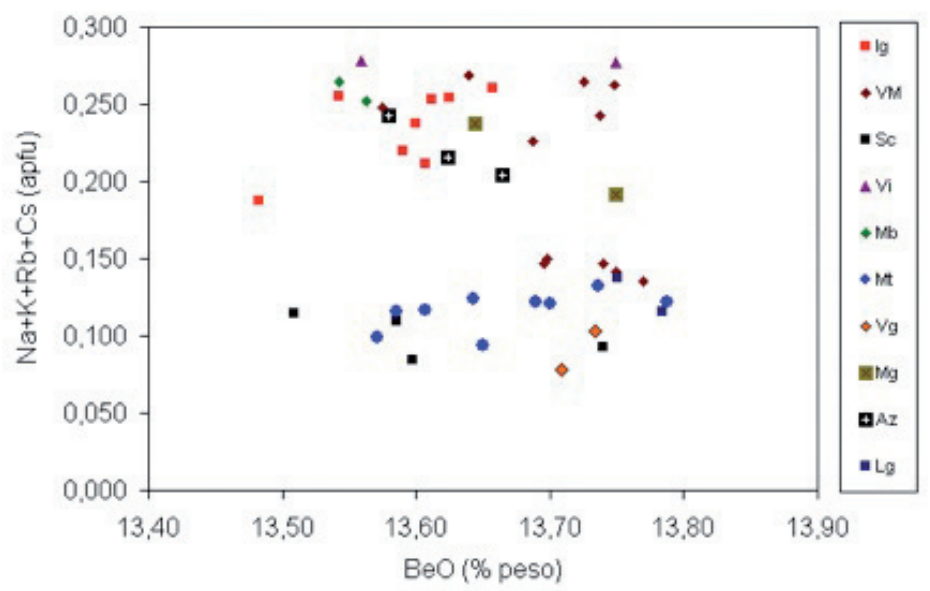

Fig. 6 - Correlação entre $\mathrm{BeO}$ e $\mathrm{Na}+\mathrm{K}+\mathrm{Rb}+\mathrm{Cs}$.

A correlação entre $\mathrm{BeO}$ e álcalis $(\mathrm{Na}+\mathrm{K}+\mathrm{Rb}+\mathrm{Cs}-\mathrm{Li})$ é muito fraca (Fig. 6), no entanto, observa-se uma distinção que parece ser abrangente entre as composiçôes dos berilos de pegmatitos menos afetados por evolução em subsolidus que se projetam a valores mais baixos.

\section{5-Conclusóes}

1. A melhor qualidade de água-marinha relaciona-se com os mais altos teores de $\mathrm{Fe}$ e de álcalis ( $\mathrm{Na}, \mathrm{K}, \mathrm{Cs}$ e $\mathrm{Rb}$ ) na malha de berilo. Tendências evolutivas secundárias, que sobrevêm após a deformação e lixiviação hidrotermal daqueles constituintes, opacificam e danificam os cristais.

2. Os berilos com maior tendência gemológica são corpos cristalinos de pequenas dimensôes ( $<8 \mathrm{~cm}$ e a $<1,5 \mathrm{~cm}$ ) em corpos filoneanos pouco possantes $(<1,5 \mathrm{~m})$ e extensos $(<20 \mathrm{~m})$ ou corpos cristalinos de grandes dimensóes, nas suas porçóes nodulares ou ocelares internas, menos afetadas pela deformação, hidrólise e deformação sobrepostas. 
3. No caso dos pequenos cristais, em pequenos pegmatitos, a cor azul é persistente, primária e precoce. O Fe pode ser incorporado por contaminaçáo do magma pegmatítico por transferência de constituintes de rochas meta-ultramáficas a máficas encaixantes. $\mathrm{O}$ facto de os corpos pegmatíticos serem pouco possantes favorece a dissipação do esforço sobreposto, de forma dúctil e nas rochas mais pelíticas encaixantes, e assim, a qualidade gemológica dos berilos mantém-se pouco afetada.

4. No caso de grandes cristais em grandes pegmatitos, a cor azul é também primária e precoce, mas não é tão persistente, dado que uma deformação de carácter menos frágil permite ruturas periféricas dos berilos que abrem acesso aos fluídos hidrotermais. No entanto, podem persistir ocelos ou nódulos de berilos de muito boa qualidade ainda preservados em gigacristais de qualidade pobre.

Agradecimentos - O CIG-R é suportado pelo programa Plurianual da Fundação para a Ciência e Tecnologia (FCT) e pelo orçamento nacional da República Portuguesa. O presente trabalho recebeu apoio da Fundação Calouste Gulbenkian através de uma bolsa de doutoramento (P-119860 (M)), e do Museu Nacional de Geologia de Moçambique para a realização dos trabalhos de campo.

\section{Referências Bibliográficas}

DIAS, P. A., GOMES, C. L. \& MARQUES, J. (2008) - Caracterização Estrutural e Paragenética do Campo Pegmatítico do Licungo (Mocuba, Moçambique) - Identificação de Recursos Base Associados. Apresentado no $5^{\circ}$ Congresso Luso-Moçambicano de Enga 6 p.

MOIANA (2010) - Certeza Geológica de Ocorrência e Viabilidade Económica para o Aproveitamento das Águas-Marinhas "True Blue” do Licungo, Zambézia-Moçambique. Tese de mestrado, Universidade do Minho, $120 \mathrm{p}$.

MOIANA, M., GOMES, C. A. L, DIAS, P. A. \& MARQUES, J. (2010) - Enquadramento Geotectónico e Filiação dos pegmatitos do Rio Licungo - Zambézia, Moçambique. VIII Congresso Nacional de Geologia em Portugal, 20, nr. 10. e-terra.

FRANZ, G., GRUNDMANN, G. \& ACKERMAND, D. (1986) - Rock Forming Beryl from a Regional Metamorphic Terrain (Tauern Window, Austria): Parageneses and Crystal Chemistry. Tschermaks Mineralogische und Petrographische Mitteilungen, 35, p. 167-192.

POlli, G. O., OliveirA, E. F., SABiOni, A. C. S., FERREIRA, A. C. M. \& ROESER H. M. P. (2006) - Análise da Composição Química em Variedades de Berilo, por Activação Neutrónica Instrumental (INAA). Geochimica Brasiliensis, 20, p. 191-207.

TVERIANKIN, I. G., BORODANOV, V. M. \& VANTCHUGOV L. G. (1983) - Relatório Sobre Os Trabalhos de Pesquisa, Prospecção e Avaliação dos Pegmatitos de Metais Raros Executados na Regiáo NE, Centrais e do SW de Alto-Ligonha em 1982-1983. Relatório nr. 1545/988, Nampula. 